\title{
SARS: epidemiology
}

\author{
MoIRA CHAN-YEUNG ${ }^{1}$ AND RUI-HENG XU² \\ ${ }^{1}$ The University of Hong Kong, Hong Kong, SAR, ${ }^{2}$ Centre for Diseases Control, Guangzhou, China
}

\begin{abstract}
SARS: epidemiology
M CHAN-YEUNG, R-H XU. Respirology 2003; 8: S9-S14

Severe acute respiratory syndrome (SARS) originated in Southern China in November 2002, and was brought to Hong Kong in February 2003. From Hong Kong, the disease spread rapidly worldwide but mostly to Asian countries. At the end of the epidemic in June, the global cumulative total was 8422 cases with 916 deaths (case fatality rate of $11 \%$ ). People of all ages were affected, but predominantly females. Health care workers were at high risk and accounted for one-fifth of all cases. Risk factors for death included old age and comorbid illnesses, especially diabetes. The disease is caused by a novel coronavirus and is transmitted by droplets or direct inoculation from contact with infected surfaces. Contaminated sewage was found to be responsible for the outbreak in a housing estate in Hong Kong affecting over 300 residents. The mean incubation period was 6.4 days (range 2-10). The duration between onset of symptoms and hospitalisation was from 3 to 5 days. The relatively prolonged incubation period allowed asymptomatic air travellers to spread the disease globally. The number of individuals infected by each case has been estimated to be 2.7. Effective control of nosocomial transmission included early detection of disease, strict isolation of patients, practice of droplet and contact precautions and compliance with the use of personal protective equipment. Effective control of disease spread in the community included tracing and quarantine of contacts. Development of a validated diagnostic test and an effective vaccine as well as elimination of possible animal reservoirs are measures needed to prevent another epidemic.
\end{abstract}

Key words: epidemiology, fatality rate, risk factors, severe acute respiratory syndrome, transmission.

\section{INTRODUCTION}

Severe acute respiratory syndrome (SARS) is the first new disease of the 21st century that poses a threat to international health with global epidemic potential. The disease first emerged in mid November 2002 in Guangdong Province, China. ${ }^{1}$ Once it reached Hong Kong in late February, the disease spread very rapidly to other parts of the world by international air travel. ${ }^{1}$ The rapidity with which the disease has spread indicated that the causative agent is infectious and virulent. The relatively long incubation period of up to 10 days $^{2}$ allows the virus to be transported globally by air travellers, many of whom did not show any symptoms of illness prior to their travel. The World Health Organization (WHO) named this atypical pneumonia 'Severe Acute Respiratory Syndrome (SARS)' because of its severity. ${ }^{3}$ The cost to the economy has been esti-

Correspondence: Moira Chan-Yeung, University Department of Medicine, 4/F, Professorial Block, Queen Mary Hospital, Hong Kong, SAR, China, Tel. 852-2855-4385; Fax: 852-2855-1143; E-mail: mmwchan@hkucc.hku.hk mated to be US $\$ 30$ billion in the Far East alone. ${ }^{4}$ The WHO and several governments issued travel advice to hard-hit areas. Hospitals, schools and borders were closed. In addition to the thousands of individuals who contracted the disease and the hundreds who died from it, thousands were quarantined and isolated. Severe acute respiratory syndrome affected every aspect of living for the citizens in hard-hit areas.

The purpose of this article is to examine the history of the outbreak and the epidemiology of the disease.

\section{HISTORY OF THE OUTBREAK AND THE CUMULATIVE NUMBER OF CASES AND DEATHS IN VARIOUS COUNTRIES IN THE ASIAN-PACIFIC REGION}

Table 1 shows the global cumulative total cases of probable SARS and the number of deaths from it at the conclusion of the epidemic. ${ }^{5}$ The epidemic curves of probable cases of SARS by week of onset worldwide and the various Asian-Pacific countries are shown in Fig. 1. In China, the epidemic curve was by the week of reporting rather than by the week of onset of disease. 
Table 1 Cumulative number of cases of SARS and deaths globally and in Asian-Pacific Region, November , 2002-August 7, 2003

\begin{tabular}{lrrr}
\hline Country & Cumulative number of cases & Number of deaths & Case-fatality rate \% \\
\hline Australia & 5 & 0 & - \\
Canada & 251 & 41 & 7 \\
China & 5327 & 349 & 17 \\
Hong Kong, SAR, China & 1755 & 300 & 11 \\
Taiwan & 346 & 37 & - \\
Indonesia & 2 & 0 & - \\
Malaysia & 5 & 2 & - \\
New Zealand & 1 & 0 & - \\
Philippines & 14 & 2 & \\
Korea & 3 & 0 & - \\
Singapore & 238 & 33 & \\
Thailand & 9 & 2 & \\
Vietnam & 63 & 5 & \\
Global & $\mathbf{8 0 9 8}$ & $\mathbf{7 7 4}$ & \\
\hline
\end{tabular}

\section{China}

This disease could be traced to the province of Guangdong, China in mid-November, 2002. On February 11, the WHO received reports from the Chinese Ministry of Health of an outbreak of 305 cases with five deaths of acute respiratory syndrome in Guangdong, China. ${ }^{1}$ No further information was provided until March 26, 2003 when China updated its numbers; there were a total of 792 cases and 31 deaths. ${ }^{6}$ China began daily reporting of SARS cases in early April. By April, the epidemic has spread and reached its peak in Beijing and several parts of China without the central government recognizing the seriousness of the situation. On April 20, China removed the national health minister and the city mayor of Beijing for their poor handling of the SARS crisis and pledged full cooperation with the WHO. ${ }^{7}$ Control measures including isolation, contact tracing and quarantine, supported by the highest level of government, resulted in a rapid decline of cases in that country. The WHO removed their travel advice and the list of areas with recent local transmission from Beijing on June $24 .{ }^{8}$

China accumulated a total of 5327 probable cases with 349 deaths at the conclusion of the epidemic. It has a case fatality ratio of $7 \%$.

\section{Hong Kong}

Severe acute respiratory syndrome was brought to Hong Kong on February 212003 by an infected medical doctor from Guangdong, China who checked into Hotel M. From Hong Kong it spread rapidly to Hanoi, Toronto and Singapore. It has been estimated that at least 12 guests and visitors to the ninth floor of Hotel $\mathrm{M}$ in Hong Kong became infected through contact with this medical doctor, in ways that remain as yet unknown, and initiated outbreaks in these places.

The index case of Hong Kong's first outbreak visited another guest on the same floor of this hotel. The index case was admitted to the Prince of Wales Hospital where he infected directly and indirectly 138 hospital staff, patients and visitors from March 11 to March 25, 2003. ${ }^{9}$ At that time, SARS had not yet been recognized as a highly infectious disease. The disease involving health care workers initially was spread very rapidly to the community by visitors to the ward.

The major SARS outbreak in the community occurred in Amoy Gardens, a high-rise apartment complex, infecting 329 residents in late March. This outbreak could be traced back to a patient discharged from the same ward of Prince of Wales Hospital. ${ }^{10} \mathrm{~A}$ high proportion of patients with SARS in Hong Kong could be linked with the first index case but the exact proportion is not known at present. The porous border between Hong Kong and southern China rendered the epidemic hard to control.

\section{Vietnam}

Severe acute respiratory syndrome was first identified in Vietnam on February 28 by Dr Carlo Urbani, a WHO epidemiologist, who died of the disease later in Thailand. ${ }^{11}$ Dr Urbani examined a Chinese-American who travelled to Hanoi via Hong Kong and stayed in Hotel $\mathrm{M}$ on the same floor as the medical doctor from Guangdong. The Vietnamese Government collaborated very closely with the WHO to bring the disease under control very quickly. In Hanoi, the cumulative number of cases was only 63 and it was removed from the list of areas with local transmission as early as April 28. ${ }^{11}$

\section{Singapore}

Three guests from Hotel $\mathrm{M}$ returned to Singapore in late February. On March 6, 2003, the Ministry of Health was notified of three persons with pneumonia; these included two of the three travellers. The out- 

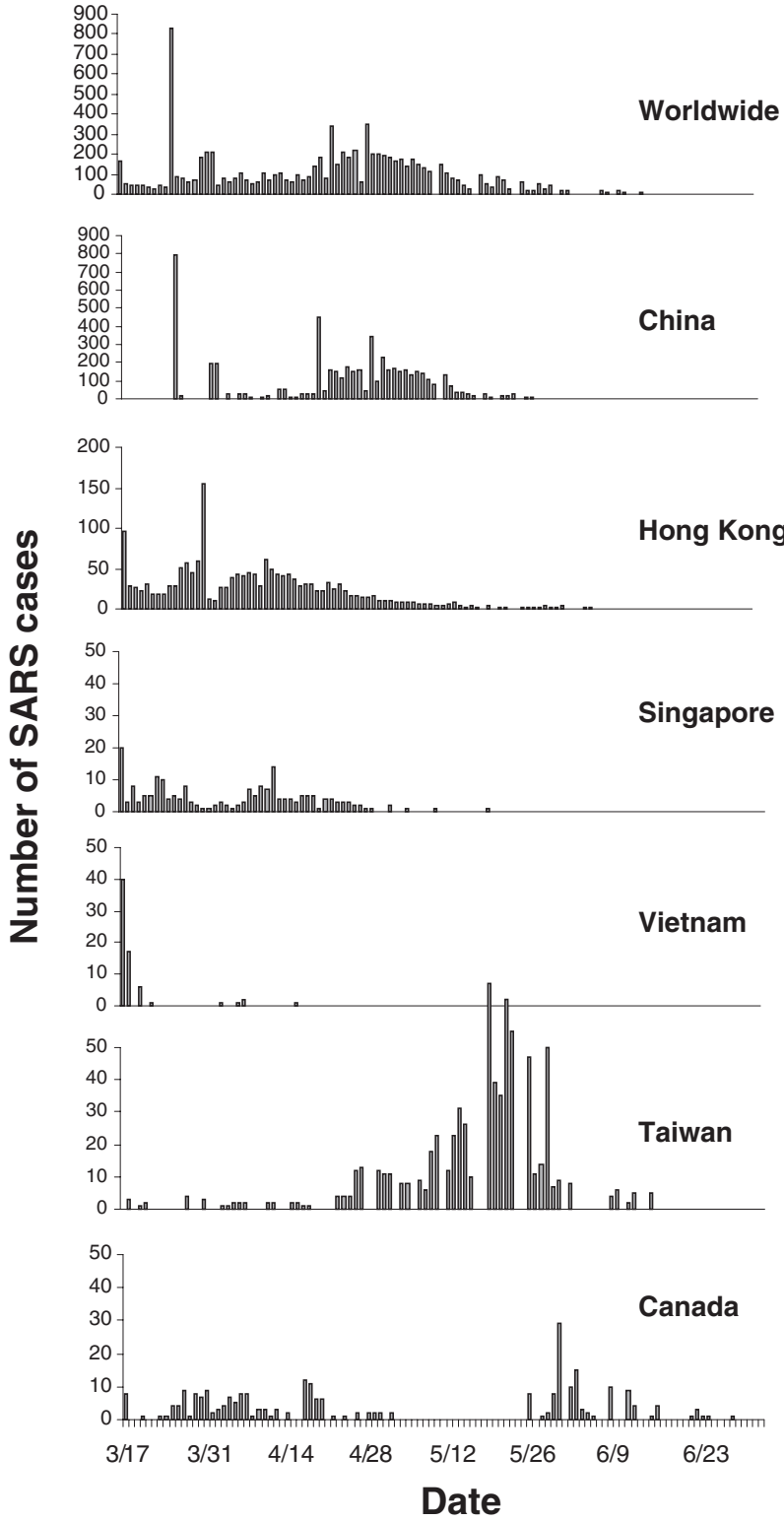

Figure 1 Probable cases of SARS by date of onset or reporting-Worldwide, China, Hong Kong, Vietnam, Singapore, Canada, and Taiwan. From: http://www.who.int/csr/sars/ epicurve/epiindex/en/index2.htm

break in Singapore had been characterized by nosocomial transmission caused by persons who were not immediately recognized as having SARS..$^{12}$ The first major extension of the illness outside the health care setting was from a SARS patient to two taxi drivers and the patient's coworkers in a wholesale market. Swift action by health authorities in conducting contact tracing, enforcing isolation and quarantine limited the spread of the disease. ${ }^{12}$

\section{Canada}

Toronto was among the first areas affected when one of the guests from Hotel $\mathrm{M}$ in Hong Kong returned home in late February. ${ }^{13}$ The outbreak in Toronto occurred early, as in Hong Kong and Singapore, when the nature of the disease was not known. Severe acute respiratory syndrome spread rapidly within hospitals and then out into wider community when other patients, hospital visitors and close contacts of staff became infected. Toronto had two outbreaks. The city was removed from the list of 'areas with recent local transmission' on May 14 only to return on May 26 when the virus surfaced in another outbreak. The city was finally declared free from local transmission on July $2 .{ }^{13}$ The case fatality ratio is $17 \%$ in Canada.

\section{Taiwan}

Taiwan's first case of SARS occurred on March 8 in a businessman with a travel history in late February to Guangdong province, China. The outbreak in Taiwan initially grew slowly with only 23 probable cases detected in the first month. The outbreak escalated in mid-April when the disease spread rapidly within a hospital and later into the community following a lapse in infection control procedures. Following this, efforts were intensified to tighten hospital infection control measures, isolation, quarantine and surveillance together with mass education campaigns. This resulted in breaking the chain of disease transmission. Taiwan had the third largest outbreak and was the last to be removed from the list of areas with recent local transmission. ${ }^{14}$ The case fatality ratio was $27 \%$.

\section{DEMOGRAPHIC CHARACTERISTICS OF THE PATIENTS}

Table 2 shows the demographics of the patients in different places. There was a predominance of females in all series. ${ }^{15-18}$ People of all ages were affected and the median age was below 45 years. Hospital workers accounted for $22 \%$ of all cases in Hong Kong ${ }^{15}$ and $22.8 \%$ in Guangdong. ${ }^{18}$ In Canada ${ }^{16}$ and Singapore, ${ }^{17}$ the proportion of affected health care workers was higher, 43 and $41 \%$, respectively. The age and sex distribution of SARS in Hong Kong is shown in Figure 2; $61.7 \%$ of patients under 45 years of age, $21.2 \%$ between 45 and 64 years and the remaining were above 64 years of age. ${ }^{15}$ Eleven $(8.14 \%)$ out of 135 early community cases without a history of contact with SARS patients were due to animal exposure. ${ }^{18}$

The case-fatality ratio in Hong Kong increased with age as in other parts of the world: $14.7 \%$ in persons under 44 years of age, $21.4 \%$ between 45 and 64 years and $63.9 \%$ over 64 years (Fig. 3). ${ }^{15}$ The experience in Hong Kong and other areas suggested that deaths were associated with pre-existing illnesses in the older age group (>64 years). ${ }^{15}$

\section{THE VIRUS AND ITS TRANSMISSION}

In order to understand the epidemiology of the disease, it is necessary to know the causative organism. 
Table 2 Characteristics of patients in different cities

\begin{tabular}{|c|c|c|c|c|c|c|}
\hline Region & $\begin{array}{l}\text { Probable } \\
\text { cases } n\end{array}$ & Female $n(\%)$ & $\begin{array}{c}\text { Age (year) } \\
\text { median (range) }\end{array}$ & $\begin{array}{l}\text { Hospital } \\
\text { staff } n(\%)\end{array}$ & $\begin{array}{l}\text { Incubation (days) } \\
\text { median (range) }\end{array}$ & Author \\
\hline Hong Kong & 1750 & $975(55.7)$ & - & $392(22.4)$ & - & $\mathrm{DH}, \mathrm{HK}$ \\
\hline Toronto & 149 & $90(61.0)$ & $45(34-57)$ & $73(51.0)$ & $6(3-10)$ & Booth et al. \\
\hline Singapore & 201 & $132(66.0)$ & $36(4-90)$ & $84(42.0)$ & $5(1-10)$ & MMWR \\
\hline Guangzhou & 190 & $120(63.2)$ & $28.6 \pm 10.3$ & $60(31.6)$ & $3 \pm 4(2-15)$ & Zhao et al. \\
\hline
\end{tabular}

DH, Department of Health; HK, Hong Kong
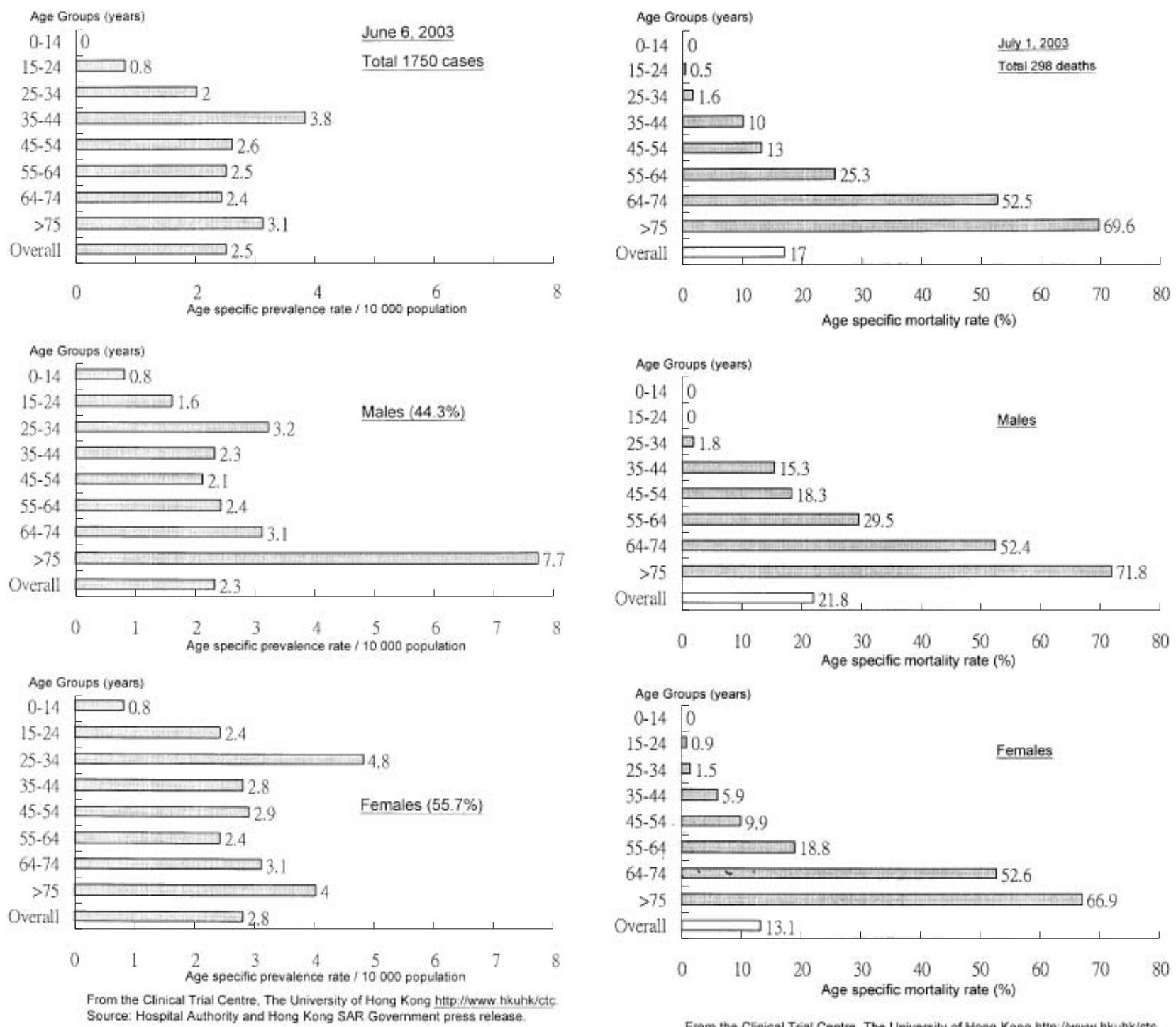

Figure 2 SARS Statistics for Hong Kong. Age and gender specific prevalence rate. From http://www.hku.hk/ctc/ sars_hk_22.htm

Within three weeks of the outbreak in Hong Kong, the microorganism responsible for the disease was identified by scientists at the University of Hong Kong to be a novel coronavirus. ${ }^{19,20}$ This was subsequently

confirmed by several other groups. ${ }^{20,21}$ The genome of this virus was sequenced, also within two months. ${ }^{22-25}$ Coronaviruses are known to be associated with a variety of diseases in humans and domestic animals,

Figure 3 SARS Statistics for Hong Kong. Age and gender specific fatality rate. From http://www.hku.hk/ctc/ sars_hk_23.htm 
including respiratory tract infections (common cold in humans) and gastroenteritis. ${ }^{26}$ It has been postulated that the proximity of humans to wild animals might have led to animal pathogens jumping across species from animals to humans, and become the causative pathogen in the latter. It is important to determine whether there is an animal reservoir, as breaking transmission of the virus may be more difficult and a recurrence of the disease is more likely.

While some investigators suggested that the virus mutates rapidly, as the strain responsible for the Amoy Gardens outbreak appeared to cause a more serious disease with diarrhoea as a prominent feature, scientists in Singapore found that the virus is rather stable. ${ }^{25}$

Preliminary studies of samples from patients using reverse transcriptase polymerase chain reaction (RTPCR) technique have demonstrated the presence of the RNA of SARS-virus in nasopharyngeal aspirate (NPA) in $31 \%$ on day $2,43 \%$ on day $3-5$, and $60 \%$ of patients from 6 to 8 days to 2 weeks after onset of the illness and in stool samples in almost $100 \%$ of patients at the end of 2 weeks. ${ }^{27}$ Thirty-two out of $316(10 \%)$ exposed asymptomatic subjects had positive RT-PCR for coronavirus in their NPA. ${ }^{27}$ It is unknown at present whether asymptomatic carriers are infectious or not, a factor important for disease control. Moreover, it is not known how long a patient can remain infectious as virus has been found in stool samples as long as one month after the onset of illness.

The virus is transmitted from human to human by droplets generated by coughing and sneezing and by direct inoculation. Contact with infected droplets on a surface can be a source of infection. Fortunately, the virus loses its infectivity after exposure to several commonly used disinfectants such as Clorox, $75 \%$ ethanol and fixatives such as formaldehyde and paraformaldehyde. ${ }^{28}$

The large number of residents in Amoy Gardens developing disease within a short period of time raised the suspicion that other modes of transmission such as airborne or oral-fecal route may be responsible. Investigation conducted by the Department of Health, Hong Kong concluded that the virus was carried by droplets into people's bathrooms as a result of contamination of waste drainage pipes and failure of the U-shaped water-seal. ${ }^{10}$ The contamination could be traced to a patient who had loose stools when he visited his brother in one of the flats in E Block of Amoy Gardens. The report excluded airborne transmission, but clear evidence has yet to be provided.

\section{DETERMINANTS OF THE EPIDEMIC}

The key epidemiological determinants of the magnitude of the epidemic include the interval between infection and the onset of symptoms, and between onset and hospital admissions, and the extent of contact and mixing between infectious and susceptible population. Studies in Hong Kong have shown that the mean incubation period is 6.4 days (1-11 days); the mean time from onset of symptoms to hospitalization varied between 3 and 5 days, with longer time earlier in the epidemic. ${ }^{29}$ Shortening the time between onset of clinical symptoms and admission to hospital should reduce the risk of onward transmission. Among staff who developed SARS in a local hospital, the mean time between onset of symptoms and hospital admission was 2 days. None of the family members of these staff were infected. ${ }^{30}$ Thus, early reporting of symptoms, hospital admission and isolation should be promoted. It has been estimated that each SARS patient was responsible for transmitting disease to 2.7 people in the community during the early part of the epidemic. ${ }^{31}$

\section{PREVENTION OF SARS AND SIMILAR INFECTIOUS DISEASE IN THE FUTURE}

Southern China has been the birthplace of various epidemics of 'flu' in the past. This is explained by the fact that its people, pigs and domestic fowl, which all harbour influenza viruses, live close together, thus increasing the likelihood that strains of virus may recombine genetically to become a new variant that is pathogenic to humans. We need to be prepared to deal with the occurrence of another epidemic in the future.

Current control measures for SARS including early case detection and isolation, tracing and follow up of contacts, and quarantine are effective but intensive both in time and cost as well as being socially disruptive. Few countries can sustain such efforts over time. One of the most important questions for the future is whether SARS can be eliminated. Three possible ways of interrupting transmission include the availability of an effective vaccine; an accurate, sensitive and specific test for early diagnosis; and the absence of an animal reservoir. There is an urgent need for an accurate and rapid diagnostic test and an effective vaccine.

Very little is known or understood about the origins of the SARS virus and the possible role, if any, that animals play in the transmission cycle. Comparison of the genetic sequences of the viruses found in different animals should make it possible to trace the evolution of the SARS virus and determine which animal passed the disease to humans. Additional studies are urgently needed.

The reporting of an outbreak of infectious disease as early as possible to the WHO is absolutely essential for containment and control. A much greater communication between health authorities of neighbouring regions is needed when an outbreak of infectious disease is suspected in order to alert the medical profession to a potential problem. The teaching and training of the medical profession in infectious diseases and the capacity of the public health sector to deal with these diseases have to be strengthened locally.

The environmental conditions that led to the spread of disease have to be dealt with. The public needs education, health promotion and reminder on personal and public hygiene. Finally, the close interaction between humans, livestock and wild animals should be discouraged. Abandoning the widespread use of exotic animals as food or traditional medicine 
and the practice of central slaughtering of livestock and fowl will decrease the chance of viruses jumping from animals to humans.

\section{REFERENCES}

1 World Health Organization. Acute respiratory syndrome in Hong Kong Special Administration of China/Vietnam. [Cited 12 March, 2003.] Available from URL: http:// www.who.int/csr/2003_03_12/en

2 Tsang KW, Ho PL, Ooi G et al. A cluster of cases of severe acute respiratory syndrome in Hong Kong. N. Engl. Med. J. 2003; 348: 1977-85.

3 World Health Organization. Severe acute respiratory syndrome (SARS)—multi-country outbreak. [Cited 15 March, 2003.] Available from URL: http://www.who.int/ csr/2003_03_15/en

4 World Health Organization. Severe acute respiratory syndrome (SARS). Status of the outbreak and lessons for the immediate future. Communicable Disease Surveillance and Response 20 May 2003. Available from URL: http:// www.who.int/csr/media/sars_who.pdf

5 World Health Organization. Summary of probable SARS cases with onset of illness from 1 November 2002 to 31 July 2003. [Cited 15 July, 2003.] Available from URL: http://www.who.int/csr/2003_10_15/en

6 World Health Organization. Severe acute respiratory syndrome (SARS) multi-country outbreak- Update 10. [Cited 26 March, 2003.] Available from URL: http:// www.who.int/csr/2003_03_26/en

7 World Health Organization. Severe acute respiratory syndrome (SARS) multi-country outbreak- Update 34. [Cited 20 April, 2003.] Available from URL: http:// www.who.int/csr/2003_04_20/en

8 World Health Organization. Update 87- World Health Organization changed its remaining travel recommendation- for Beijing, China. [Cited 15 March, 2003.] Available from URL: http://www.who.int/csr/2003_06_24/en

9 Lee N, Hui D, Wu A et al. A major outbreak of severe acute respiratory syndrome in Hong Kong. N. Eng. J. Med. 2003; 358: 1986-94.

10 Department of Health, Hong Kong. Main findings of an investigation into the outbreak of Severe Acute Respiratory Syndrome at Amoy Gardens. [Cited 17 April, 2003.] Available from URL: http://www.info.gov.hk/dh

11 World Health Organization. Severe acute respiratory syndrome (SARS) multi-country outbreak. [Cited 12 April, 2003] Available from: http://www.who.int/csr/ 2003_04_12/en

12 World Health Organization. Update 70- Singapore removed from list of areas with local SARS transmission. [Cited 30 May, 2003.] Available from URL: http:// www.who.int/csr/2003_05_30/en

13 World Health Organization. Update 93-Toronto removed from list of areas with recent local transmission. [Cited April 17, 2003.] Available from URL: http:// www.who.int/csr/2003_07_02/en

14 World Health Organization. Update 96-Taiwan, Chin SARS. transmission interrupted in last outbreak area. [Cited 2 July, 2003.] Available from URL: http:// www.who.int/csr/2003_07_02/en

15 Clinical Trials Centre. SARS Daily Updated Graphs. [Cited 20 June, 2003.] Available from URL: http:// www.hku.hk/ctc/sars_hk_23.htm
16 Booth CM, Matukas LM, Tomlinson GA et al. Clinical features and short-term outcomes of 144 patients with SARS in the Greater Toronto area. JAMA 2003; 289: 28019.

17 Morbidity and Mortality Weekly Report. Severe acute respiratory syndrome-Singapore. JAMA 2003; 289: 32314.

18 He J-F, Xu R.-H, YuD-W et al. Severe acute respiratory syndrome in Guangdong Province of China: epidemiology and control measures. Chin. J. Prev. Med. 2003; 37: 227-32.

19 Peiris JSM, Lai ST, Poon LLM et al. Coronavirus as a possible cause of severe acute respiratory syndrome. Lancet 2003; 361: 1319-25.

20 Ksiazek TG, Erdman D, Goldsmith CS et al. A novel coronavirus associated with severe acute respiratory syndrome. N. Engl. J. Med. 2003; 348: 1953-66.

21 Drosten C, Gunther S, Preiser W et al. Identification of a novel coronavirus in patients with severe acute respiratory syndrome. N. Engl. J. Med. 2003; 348: 196776.

22 Atlanta Centres for Diseases Control and Prevention. CDC Laboratory sequences genome of new coronavirus. [Cited April 16, 2003.] Available from URL: http:// www.cdc.gov/od/oc/media/pressrel/r030414.htm

23 Rota PA, Oberste MS, Monroe SS et al. Characterization of a novel coronavirus associated with severe acute respiratory syndrome. Science 2003; 300: 1394-9.

24 Marra MA, Jones SJM, Astell CR et al. The genome sequence of the SARS-associated coronavirus. Science 2003; 300: 1399-404.

25 Ruan YJLW \& Chia AE Ling et al. Comparative fulllength genome sequence analysis of 14 SARS coronavirus isolates and common mutations associated with putative origins of infection. Lancet 2003; 361: 1779-85.

26 World Health Organization. Severe acute respiratory syndrome (SARS). [Cited $24 \mathrm{March}$, 2003.] Available from URL: http://www.who.int/csr/2003_03_24/en (civet cat).

27 Peiris JSM, Chu CM, Cheng VCC et al. Clinical progression and viral load in a community outbreak of coronavirus-associated SARS pneumonia: a prospective study. Lancet 2003; 361: 1767-72.

28 World Health Organization. First data on stability and resistance of SARS coronavirus compiled by members of WHP laboratory network. [Cited 4 May, 2003.] Available from URL: http://www.who.int/csr/sars/ survival_2003_05-04/en/index.html

29 Donnelly CA, Ghani AC, Leung GM et al. Epidemiological determinants of spread of causal agent of severe acute respiratory syndrome in Hong Kong. [Cited 26 September, 2003.] Available from URL: http:// image.thelancet.com/extras/03art4453web.pdf

30 Ho A, Sung JJY, Chan-Yeung M. An outbreak of Severe Acute Respiratory Syndrome (SARS) among hospital workers in a Community Hospital in Hong Kong. Ann. Int. Med. 2003; 139: 564-7.

31 Riley S, Fraser C, Donnelly CA et al. Transmission Dynamics of the etiological agent of SARS in Hong Kong: impact of public health interventions. Sciencexpress. [Cited 23 May, 2003.] Available from URL: http:// www.sciencexpress.org/ 23 May 2003/Page 1/10.1126/ science. 1086478 